\title{
System Dynamics Modelling for Dynamic Emergency Response to Accidents Involving Transport of Dangerous Goods by Road
}

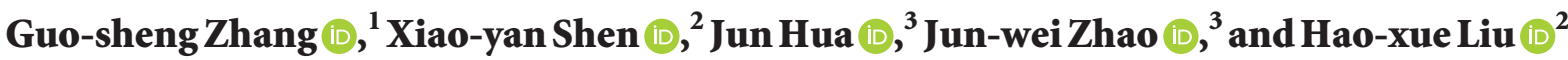 \\ ${ }^{1}$ Key Laboratory of Operation Safety Technology on Transport Vehicles, Ministry of Transport, PRC, Beijing 100088, China \\ ${ }^{2}$ School of Automobile, Chang'an University, Xi'an 710064, Shaanxi, China \\ ${ }^{3}$ School of Transportation Science and Engineering, Beihang University, Beijing 100191, China
}

Correspondence should be addressed to Xiao-yan Shen; sxy719@163.com

Received 4 July 2021; Accepted 14 September 2021; Published 18 October 2021

Academic Editor: Zhixiang Fang

Copyright (C) 2021 Guo-sheng Zhang et al. This is an open access article distributed under the Creative Commons Attribution License, which permits unrestricted use, distribution, and reproduction in any medium, provided the original work is properly cited.

\begin{abstract}
For improving the emergency capacities during road transportation accidents of dangerous goods, this paper divides the accident emergency procedure into four subsystems: accident information processing, personnel rescue and evacuation, vehicle evacuation, and rescue materials delivery. On this basis, the causal mechanism and the loop diagrams of the emergency process are established by using the System Dynamics Method and Vensim software. First, six factors including transportation distance, the degree of mechanical modernization, delay time of personnel control, delay time of traffic information release, command level coefficient, and delay time of department arrival are selected as parameters to test the model's sensitivity analysis. Then, the influences of the abovementioned factors on the observed value, such as the demand gap of on-site materials, number of people in safe area, number of vehicles in safe area, amount of disposal information, and the dynamic evolution behavior of the system, are analyzed. The results show that the transportation distance is shortened by half, and the time to fill the demand gap is reduced by $39 \%$. The level of mechanical modernization is doubled, the peak inventory of materials in transit will increase by $9.2 \%$, and the time to reach the peak will be shortened by $6.8 \%$. If the delay time of personnel control is shortened by $480 \mathrm{~s}$, the number of people to be evacuated in accident area will be reduced by 56 . The delay time of traffic information release is shortened by $480 \mathrm{~s}$, the number of vehicles to be evacuated is reduced by 74 , and the time when the vehicle stops entering accident area is $1646 \mathrm{~s}$ in advance. The command level coefficient increases by $9.5 \%$, and the speed of action execution increases by $9.6 \%$.
\end{abstract}

\section{Introduction}

Dangerous goods are an important support for the normal operation of social production and people's lives. Road transportation is the most important mode of transporting dangerous goods, accounting for more than $70 \%$ of the total volume among all modes of transportation. However, because of multiple factors including the complex hazardous properties, the mobility of vehicles, the mixed traffic flow, and unpredictable spatiotemporal, the occurrence of a sudden accident is usually accompanied by the leakage and explosion of flammable, toxic, and other harmful substances, which can cover a wide range, bring a large number of casualties and property losses, and lead to traffic congestion surrounding the affected area. It is of great significance to study the accident emergency capabilities to control the harm and consequences caused by the accident.

Aiming at the research on emergency management of transportation accidents of dangerous goods, many existing studies have focused on emergency decision-making, emergency material scheduling, emergency capability assessment, evacuation path planning, and so on. For example, Fabiano et al. [1] presented a theoretical approach for emergency planning and optimization of dangerous goods transportation. Berman et al. [2] presented a methodology to assess the emergency response capability during the transport incidents of dangerous goods. The algorithm was used for optimizing the existing specialized team network and maximizing this ability to respond to dangerous goods incidents. Chen et al. [3] proposed a quantum particle swarm 
model to analyze the regional emergency evacuation on major and core road networks during a given time. The result shows that the evacuation capability will increase by $56.9 \%$ than normal cases, if the traffic management department makes the most of the information superiority and dominant road network evacuation capacity. Kinateder et al. [4] used a five-sided CAVE system to investigate the effect of an increased risk during a simulated tunnel emergency on participants' subjective hazard perception and evacuation behavior. Hazard perception, premovement time, movement time, and exit choices were analyzed. Huang et al. [5] proposed an approach combined with self-contained Girvan-Newman algorithm and mean variance model to allocate the defense resource in road dangerous goods transportation network.

In general, due to the particularity of road transportation accidents of dangerous goods, its emergency process is complex, nonlinear, and time-varying with multiple feedbacks, which requires the collaborative management of people, administrative department, vehicles, roads, and emergency facilities. At present, the researches on the emergency of road transportation accidents of dangerous goods are insufficient. Most of the research studies in the area focus on the single segment of the accident emergency process, lacking the comprehensive understanding and macrosimulation of the entire emergency process. The influence mechanism of single factor on the behavior mode of emergency capability in complex emergency system is not well explored.

System dynamics method is a methodology that explores the feedback structure and behavior patterns of a complex system and has been widely used to deal with complex problems in the emergency management, especially the emergency resources supply and scheduling [6-10], emergency evacuation [11], hospital and emergency department [12-16], and emergency in flood disaster [17]. However, this methodology is less studied by previous scholars on the emergency management of dangerous goods transportation accidents. This paper intends to explore the emergency process of road transportation accidents of dangerous goods from a macrosystem perspective. Then, the impact of key elements on the emergency disposal ability will be simulated by using System Dynamics Model, and dynamic evolution characteristics of each factor over time will be investigated.

\section{Model Construction}

According to the investigation on the actual emergency process of road transportation accidents of dangerous goods, the emergency process usually includes two phases. The first is the information processing phase. It involves accident report and subsequent emergency procedure start-up by relevant emergency departments. The second is the emergency response phase; information about material delivery, feedback of personnel and vehicle evacuation should be given to the emergency department in real time, so as to evaluate the situation and make decisions. Therefore, taking the information of accident transfer as the main line, the scope of this study covers accident report, emergency response, emergency evacuation and rescue, and emergency disposal information feedback, and its relationship is shown in Figure 1.

For simplification, it is assumed that only a storage warehouse and one type of rescue material are involved in rescue material delivery process, and only a rescue agency is involved in rescuing people. The evacuation of people and vehicles only takes into account people and vehicles outside the accident site who could enter the accident site. People and vehicles inside the site, who are free to leave the accident site without traffic control, are not considered.

2.1. Causal Loop Diagram of the Model. The emergency process is regarded as a system composed of several subsystems, such as accident information processing, personnel rescue and evacuation, vehicle evacuation, and rescue material delivery. According to the causal relationship of various factors in the subsystem and the correlation between the subsystems, the causal loop diagram of the emergency process referring to the road transportation accidents of dangerous goods is constructed, as shown in Figure 2.

The causal loop diagram includes four feedback loops, as follows:

(1) Positive feedback loop for information processing: Information reporting- $\longrightarrow$ information receiving $+\longrightarrow$ information evaluation $+\quad \longrightarrow$ command $+\longrightarrow$ disposal- $\longrightarrow$ information feedback.

If the complexity of the accident information is low, it is conducive to the smooth development of a series of works such as information reception, evaluation, command, and disposal, so as to restrain the continuous increase of the information complexity. After the complexity of information is regulated by the process of accident information processing, its growth slows down or even stops due to inhibition.

(2) Positive feedback loop of personnel rescue and evacuation:

Number of people to be evacuated at accident site $+\longrightarrow$ personnel density- $\longrightarrow$ personnel speed $+\longrightarrow$ pedestrian flow $+\longrightarrow$ evacuation speed $+\longrightarrow$ number of people in safe area$\longrightarrow$ number of on-site people updating.

The continuous increase of the number of people to be evacuated gradually increases the personnel density on the road available for evacuation, slows down the pedestrian movement speed, and reduces the pedestrian flow per unit time, which slows down the evacuation speed. The traffic control department should guide the affected people to evacuate to the safe area. However, because the evacuation speed can be affected by subjective and objective reasons, the increase of the number of people in the safe area is restrained and the growth is slow.

(3) Positive feedback loop of vehicle evacuation:

Number of vehicles to be evacuated at accident site $+\longrightarrow$ traffic-flow density $\quad \longrightarrow$ vehicle 


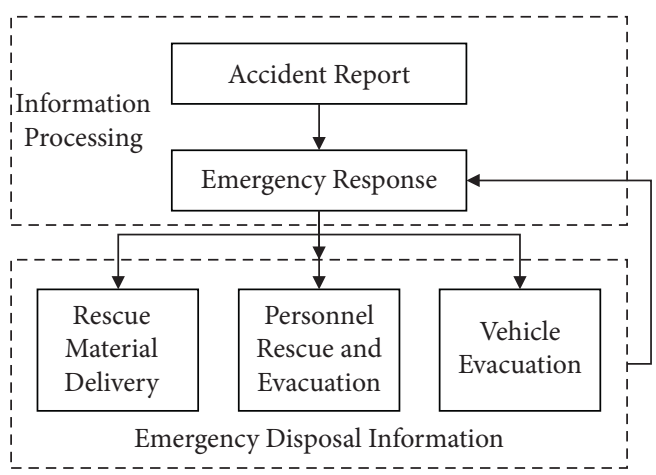

FIGURE 1: Basic framework of emergency procedures of road transportation accidents of dangerous goods.

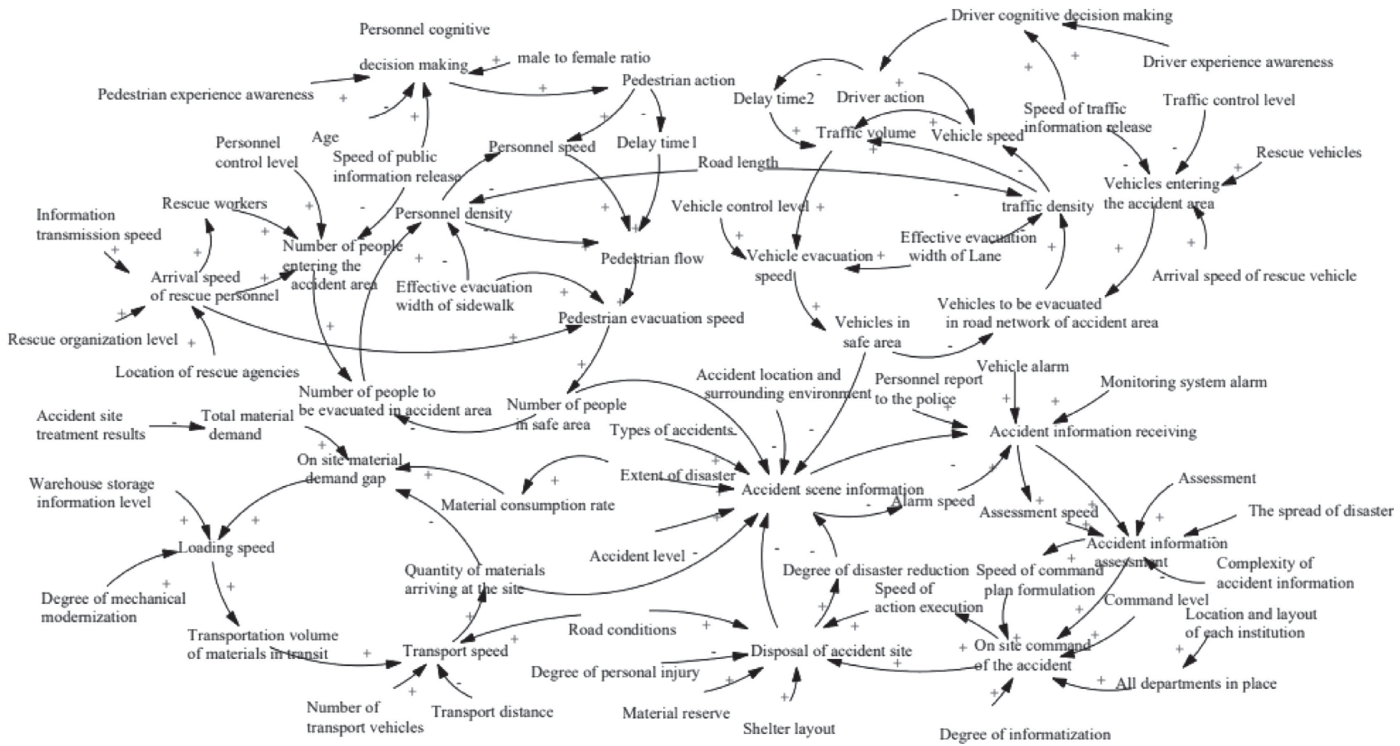

FIGURE 2: Causal loop diagram of emergency procedures.

speed $+\longrightarrow$ traffic volume $+\longrightarrow$ evacuation speed $+\longrightarrow$ the number of vehicles in the safe area$\longrightarrow$ number of on-site vehicles updating.

The increase of vehicles to be evacuated will increase the traffic-flow density, slow down the driving speed, and decrease the traffic flow per unit time during the evacuation process. Then, the evacuation speed will slow down, the number of vehicles transferred to the safe area increases slowly, and the number of vehicles waiting for evacuation decreases slowly.

(4) Negative feedback loop for rescue material delivery: The demand gap of rescue material $+\longrightarrow$ loading speed $+\longrightarrow$ transportation volume of materials in transit $+\longrightarrow$ transport speed $+\longrightarrow$ amount of materials arriving at accident site- $\longrightarrow$ demand gap of material updating.

Due to the continuous growth of material demand, the demand gap increases, which requires the storage warehouse to speed up the loading speed, increase the transportation volume in transit, and improve the transport speed, corresponding increasing the amount of materials arriving at the site and reducing the demand gap. The supply department takes replenishment action according to the demand gap, but sometimes it cannot produce immediate effect, owing to the delay decided by the change of loading and transportation speed.

2.2. System Flowchart and Relationship Equations. This paper takes a serious road transportation accident of dangerous goods as an example. It leads to the leakage and diffusion of toxic gas and causes a large number of people to get injured and poisoned. The causal relationships in the emergency disposal process are simulated by Vensim software, and a system flowchart explaining the process was established, as shown in Figure 3.

2.2.1. Information Processing Module. Information processing at accident site is the core of the entire emergency process, which changes dynamically with the whole process. It includes the status information at the beginning of the accident and disposal information in progress. All information must be reported, received, evaluated, directed, and 


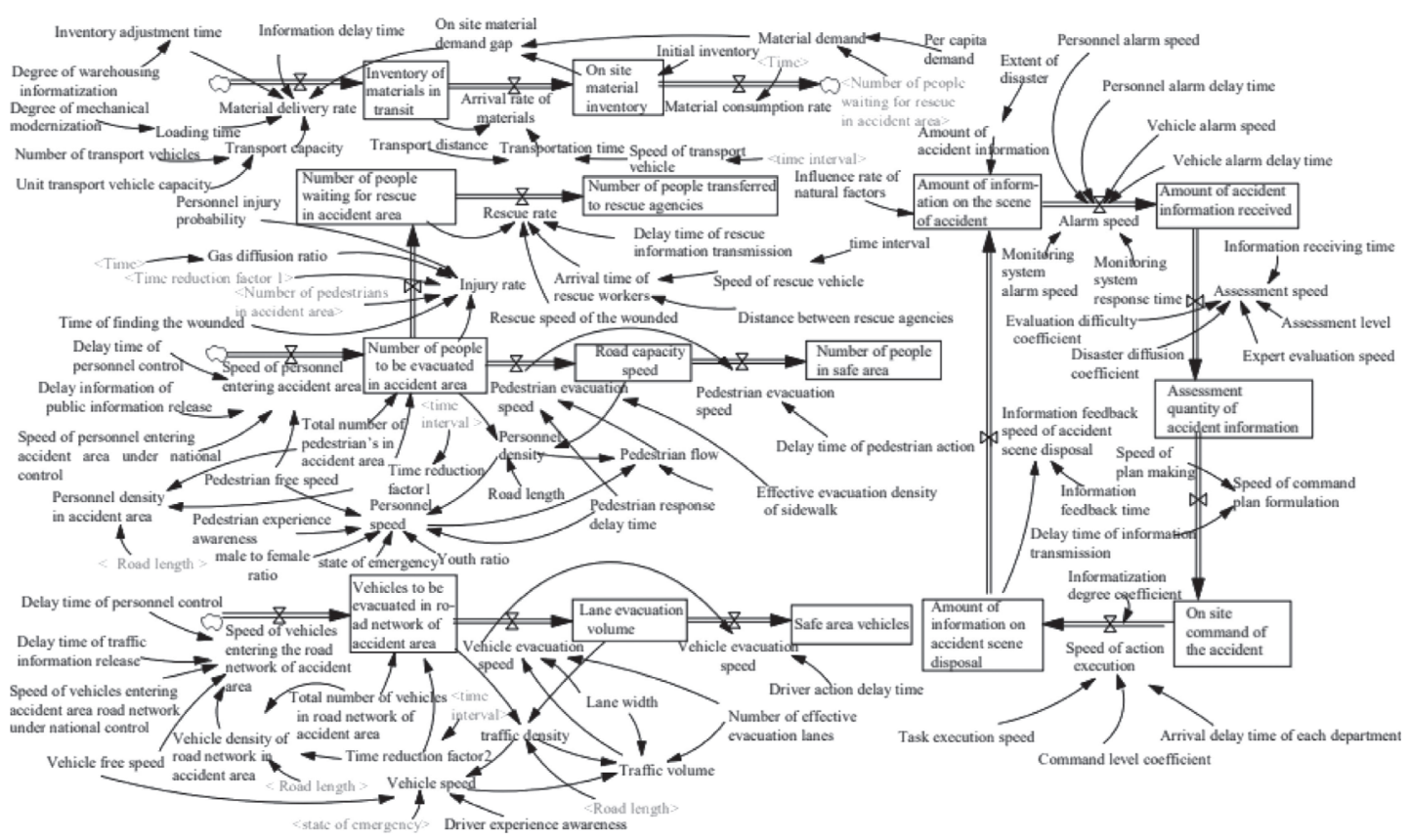

FIGURE 3: System flowchart of emergency process.

processed until the emergency process is fully completed. The main functional relationship is shown as follows:

(1) Information quantity of accident site = INTEG (Feedback speed of disposal information - Report speed, Amount of accident information $\times$ Influence rate of natural factors) (units: unit)

(2) Amount of accident information = IF THEN ELSE (Disaster degree $<4$, IF THEN ELSE (Disaster degree $<3$, IF THEN ELSE (Disaster degree $<2$, 1500, 2000)2500), 3000) (units: unit)

(3) Report speed = MAX (MAX (DELAY1I (Report speed of personnel, Delay time of personnel report, 0 ), DELAY1I (Report speed of vehicle, Delay time of vehicle report, 0)), DELAY1I (Report speed of monitoring system, Response time of monitoring system, 0)) (units: unit/s)

(4) Evaluation speed = DELAY1I (Expert evaluation speed $\times$ Evaluation difficulty coefficient $\times$ Disaster diffusion coefficient $\times$ Evaluation level, Delay time of receiving information, 0) (units: unit/s)

(5) Speed of action execution = DELAY1I (Task execution speed, Delay time of department arrival, 0$) \times$ Command level coefficient $\times$ Informationization coefficient (units: unit/s)

(6) Feedback speed of disposal information = DELAY1I (Amount of disposal information/Feedback time of information, Feedback time of information, 0) (units: unit/s)

After the occurrence of accident, the decision-making departments carry out the emergency disposal work based on predicting the accident severity and complexity of emergency disposal. The severity of the accident is divided into four levels: level 1 (especially serious), level 2 (serious), level 3 (large), and level 4 (general). The corresponding amount of accident information is 3000 units, 2500 units, 2000 units, and 1500 units, respectively.

2.2.2. Personnel Rescue and Evacuation Module. If human safety is threatened by the diffusion of toxic gases, the personnel status will change at a certain rate from "pending evacuation" to "pending rescue." The injury rate varies with the amount of leakage, the diffusion rate, and the time of finding the injured. The arrival speed of rescuers and the rescue speed directly affect the rescue rate, which is related to the release time of rescue information. Due to the delay of on-site personnel control and public information release, there are also off-site people entering accident site, while the crowd in the affected area evacuate to the safe area. The increase of people to be evacuated will directly affect the density of on-site people, thereby changing the walk speed and slowing down the evacuation process. The main functional relationship is shown as follows:

(1) Number of people waiting for rescue in accident site = INTEG (Injury rate-Rescue rate, 0) (units: person)

(2) Number of people transferred to rescue point = INTEG (Rescue rate, 0) (units: person)

(3) Injury rate $=$ IF THEN ELSE (Number of people to be evacuated in accident site $>0$, DELAY1I (Total number of passengers in accident site $\times$ Time reduction factor $1 \times$ Diffusion rate $\times$ Poisoning probability/Time of finding the injured, Time of finding the injured), 0) (units: person)

(4) Rescue rate $=$ IF THEN ELSE (Number of people waiting for rescue in accident site $>0$, DELAY1I (Rescue speed, Delay time of rescue information 
release + Arrival time of rescuers, 0), 0) (units: person)

(5) Speed of rescue vehicle = IF THEN ELSE (((Time interval $\geq 7)$ :AND:(Time interval $\leq 9)$ ): OR: ((Time interval $\geq 17)$ :AND:(Time interval $\leq 19)$ ), 7.5, 12.5) (units: $\mathrm{m} / \mathrm{s}$ )

(6) Number of people to be evacuated in accident site $=$ INTEG (Speed of entering accident site Injury rate - Pedestrian evacuation speed, Total number of passengers in accident site $\times$ Time reduction factor1) (units: person)

(7) Speed of entering accident site = DELAY1I (Speed of entering accident site under overall control, Delay time of public information release + Delay time of personnel control, Pedestrian free-flow speed) $\times$ Personnel density in accident site (units: person/s)

(8) Personnel density $=($ Number of people to be evacuated in accident site-Number of people accommodated on the road)/Road length (units: person $/ \mathrm{m}$ )

(9) Pedestrian flow $=$ Personnel density $\times$ Personnel speed/Effective evacuation width of sidewalk (units: person $/ \mathrm{m} \cdot \mathrm{s}$ )

(10) Pedestrian evacuation speed $=$ DELAY1I (Pedestrian flow $\times$ Effective evacuation width of sidewalk, Delay time of pedestrian response, 0) (units: person/s)

(11) Pedestrian evacuation speed = DELAY1I (Pedestrian evacuation speed, Delay time of pedestrian action, 0) (units: person/s)

2.2.3. Vehicle Evacuation Module. Vehicles are controlled by drivers. In the event of an accident, the driver's manipulation of the vehicle movement can be affected by the driver's own characteristics and traffic control requirements. In the process of vehicle evacuation guided by the traffic control department, the increase of vehicles evacuation volume will cause dynamic changes in the status of road traffic flow. The main functional relationship includes the following:

(1) Vehicles to be evacuated in accident site = INTEG (Speed of vehicles entering accident site - Vehicle evacuation speed, Total number of vehicles in accident site $\times$ Time reduction factor 2) (units: vehicle)

(2) Speed of vehicles entering accident site = DELAY1I (Speed of vehicles entering the accident site under overall control, Delay time of traffic information release + Delay time of traffic control, Vehicle freeflow speed) $\times$ Vehicle density in the accident site (units: vehicle/s)

(3) Vehicle evacuation speed = DELAY1I (Vehicle evacuation speed, Delay time of driver action, 0) (units: vehicle/s)
(4) Traffic-flow density $=($ Vehicles to be evacuated in accident site-Evacuation volume of lane)/Road length (units: vehicle/m)

(5) Traffic flow $=$ Traffic-flow density $\times$ Vehicle speed/ (Number of effective evacuation lanes $\times$ Lane width) (units: vehicle/m·s)

(6) Vehicle evacuation speed $=$ Traffic flow $\times$ Number of effective evacuation lanes $\times$ Lane width (units: vehicle/m)

2.2.4. Rescue Materials Delivery Module. At the accident site, the demand of rescue materials is generated to support rescue and other work. Rescue supplies are gradually consumed with the development of the rescue progress. The storage warehouse needs to continuously deliver rescue materials to accident site. The supply shortage will interrupt the rescue. The materials demand depends on the number of people to be rescued in accident site. The main functional relationships mainly include the following:

(1) Inventory of materials in transit = INTEG (Material delivery rate-Material arrival rate, 0 ) (units: unit)

(2) Inventory of on-site materials = INTEG (Material arrival rate-Material consumption rate, Initial stock) (units: unit)

(3) Material delivery rate = IF THEN ELSE (Demand gap of on-site materials $>0$, DELAY1I (Transportation capacity/Loading time, Adjustment time of stock + Delay time of Information), 0) (units: unit/s)

(4) Material arrival rate=Inventory of materials in transit/Transportation time (units: unit/s)

(5) Material consumption rate $=$ WITH LOOKUP (Time, $([(0,0)-(8000,6)],(0,0),(150,0.8),(300$, $1.5),(600,2.8),(900,4),(1200,5),(1500,5.6),(1800$, 6), (2100, 5.6), (2400, 5), (2700, 4), (3000, 2.8), (3300, $1.5),(3600,0.8),(4000,0.5),(5000,0.25),(6000,0.1)$, $(8000,0)))$ (units: unit/s)

(6) Demand gap of on-site materials = Total demand of materials-Amount of materials arriving at the site (units: unit)

(7) Demand of materials $=$ Number of people waiting for rescue in accident site $\times$ Per capita Demand (units: unit)

(8) Transportation capacity = Number of delivery vehicle $\times$ Capacity per vehicle (units: unit)

(9) Speed of delivery vehicle = IF THEN ELSE (( (time interval $\geq 7)$ : AND:(time interval $\leq 9))$ : OR: $(($ time interval $\geq 17)$ : AND: (time interval $\leq 19)), 7.5,12.5$ ) (units: $\mathrm{m} / \mathrm{s}$ )

According to a demand model of rescue material established in literature [18], the material consumption rate is not constant in the emergency process and always increases first and then decreases. In this model, it is assumed that the material consumption rate has an approximate quadratic function relationship with the emergency time. At 
the beginning, the minimum material consumption rate is 0 unit/s, and then the consumption increases in an S-shaped curve over time. After about $30 \mathrm{~min}$, the consumption rate reaches the peak value of 6 units/s and then decreases gradually to 0 unit/s at the end of the simulation. In Vensim software, the WITH LOOKUP function is used to establish the curve of material consumption rate, and the value on the curve is the consumption rate at different moments of emergency process.

\section{Simulation Modeling}

3.1. Values for Simulation Variables. Table 1 shows the values of the simulation variables required in the emergency process in the event of an accident.

3.2. Model Validation. The effectiveness of the proposed model is assessed by an extreme-conditions test. In the test, the model receives a "shock" treatment, in which one or more variables are exposed to extreme conditions. Then, the behavior and response of the model are simulated and observed to determine whether the model can reflect the change rules of the actual system and the willingness of policymaker.

For the information processing module, it was assumed that the feedback speed of disposal information is taken as half of the simulation time (=4000 s). In this setting, the accident information has not been given as feedback to the system after a series of procedures such as report, receiving evaluation, and disposal, and the emergency disposal has been completed. Then, the information quantity of accident site quickly dropped to a negative value, as shown in Figure 4.

For the vehicle evacuation module, the vehicle free-flow speed is set to 0 in a nonemergency situation. Then, the speed of entering accident site and the vehicle evacuation speed will be equal to 0 . In this setting, the number of vehicles to be evacuated in accident site remains unchanged, as shown in Figure 5.

For the personnel rescue and evacuation module, if the pedestrian free-flow speed is set to 0 in a nonemergency situation, the personnel evacuation module will stop. In this setting, the status of personnel in the affected area will change from "pending evacuation" to "pending rescue" within a certain period (see Figure 6).

For the rescue materials delivery module, the capacity per delivery vehicle is set to 0 ; that is, the transportation capacity is equal to 0 , and the results are shown in Figure 7. At this moment, due to the sudden decline of transport capacity, rescue materials in the storage point cannot be delivered normally to the accident site. Consequently, the inventory of on-site materials quickly decreases to negative value due to the increased demand after the initial stock is exhausted. The demand gap of on-site material is also expanding.

To sum up, the behavior characteristics of each module under extreme conditions are consistent with the actual situations. It is considered that the proposed model is effective.
3.3. Sensitivity Analysis of the Model. The sensitivity trend of the proposed model is tested through the sensitivity analysis methodology for extracting the major factors of the emergency disposal capability, as shown in Figure 8. The bands of different colors in the figure represent different confidence intervals of sensitivity. The wider the band is, the larger the area is, which means that the parameter has a greater impact on the sensitivity analysis target. Different targets for the sensitivity analysis are set, assuming that each parameter followed a random distribution on the corresponding interval. After running the model 200 times respectively, the sensitivity of each variable to the target is tested. The demand gap of on-site materials, the number of people in the safe zone, the number of vehicles in the safe zone, and the amount of accident information are set as the test objectives. The sensitivity analysis results and the most sensitive factors are obtained, as shown in Figure 8.

\section{Decision Analysis}

4.1. Strategy 1: Shortening the Transportation Distance. To simulate changes of the demand gap of on-site materials with the transportation distance, the transportation distance is assumed as $2000 \mathrm{~m}, 1500 \mathrm{~m}$, and $1000 \mathrm{~m}$, and the corresponding states are set as current, current1, and current2, respectively, as shown in Figure 9.

With the shortening of transportation distance, the demand gap of on-site materials decreases to varying degrees in each delivery cycle. In the first delivery cycle, the demand gap rises to the maximum at $40 \mathrm{~s}, 26 \mathrm{~s}$, and $18 \mathrm{~s}$ of the simulation periods, which are 116.4 units, 111.6 units, and 107.5 units, respectively. The gap then dropped to 0 at $156 \mathrm{~s}$, $127 \mathrm{~s}$, and $95 \mathrm{~s}$, respectively.

It can be seen that the materials in a shipment can arrive at the accident site earlier by shortening the transportation distance, and the demand gap can then be filled sooner under the condition of the same change trend of material demand.

4.2. Strategy 2: Improving the Degree of Mechanical Modernization. To simulate changes in inventory of materials in transit and the demand gap of on-site materials with the degree of mechanical modernization, the degree of mechanical modernization is assumed as 4,6 , and 8 , and represents the degrees of low, medium, and high, respectively. The corresponding states are also set as current, current1, and current2, respectively (see Figure 10).

Table 2 lists the peak value of the inventory of materials in transit and the arrival times in the first four delivery cycles and the whole simulation period.

Due to the improvement of mechanical modernization of storage warehouse and delivery vehicles, the delivery speed of materials is accelerated, and the inventory in transit is improved, which can effectively fill up the inventory gap of on-site materials.

4.3. Strategy 3: Shortening the Delay Time of Personnel Control. To simulate changes in the speed of entering accident site and the number of people to be evacuated 
TAвLE 1: Constant or initial values in simulation model.

\begin{tabular}{|c|c|c|c|c|c|}
\hline Variable & Value & Variable & Value & Variable & Value \\
\hline Time & 9:00 & Capacity per vehicle & $\begin{array}{l}500 \text { units/ } \\
\text { vehicle }\end{array}$ & Information delay time & $60 s$ \\
\hline Per capita demand & $\begin{array}{l}1 \text { unit/ } \\
\text { person }\end{array}$ & Time of finding the injured & $20 s$ & $\begin{array}{l}\text { Delay time of rescue } \\
\text { information release }\end{array}$ & $60 \mathrm{~s}$ \\
\hline Pedestrian free-flow speed & $1.2 \mathrm{~m} / \mathrm{s}$ & Male to female ratio & 0.7 & Proportion of young people & 0.9 \\
\hline $\begin{array}{l}\text { Delay time of pedestrian } \\
\text { response }\end{array}$ & $180 \mathrm{~s}$ & Delay time of pedestrian action & $30 \mathrm{~s}$ & $\begin{array}{c}\text { Total number of vehicles in } \\
\text { accident site }\end{array}$ & $\begin{array}{c}1,000 \\
\text { vehicles }\end{array}$ \\
\hline Lane width & $3.75 \mathrm{~m}$ & Delay time of driver action & $30 s$ & Evaluation difficulty coefficient & 1.05 \\
\hline Initial stock & 100 units & $\begin{array}{c}\text { Total number of passengers in } \\
\text { accident site }\end{array}$ & 2500 people & $\begin{array}{c}\text { Effective evacuation width of } \\
\text { sidewalk }\end{array}$ & $1.5 \mathrm{~m}$ \\
\hline Vehicle free-flow speed & $10 \mathrm{~m} / \mathrm{s}$ & Informationization coefficient & 1.05 & & \\
\hline
\end{tabular}

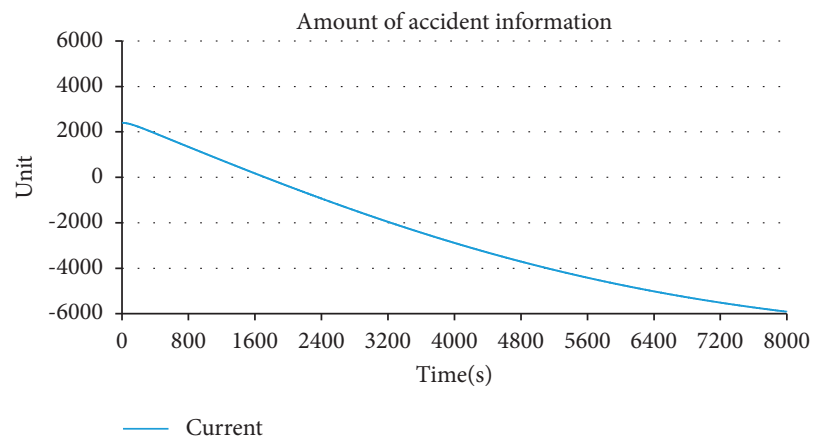

FIGURE 4: Extreme test of information processing.

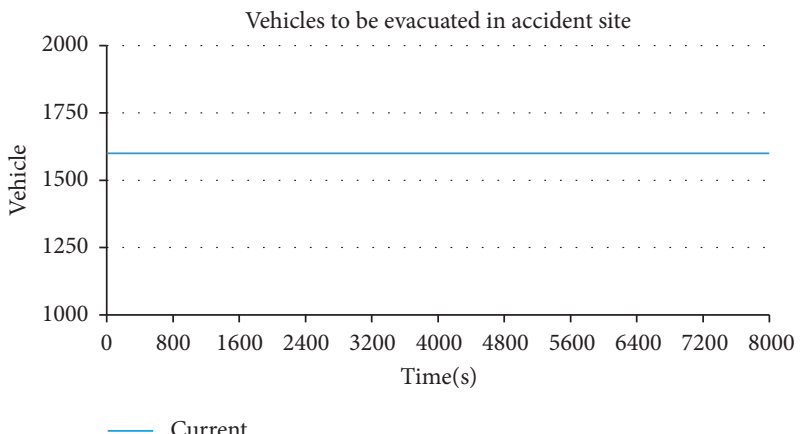

Figure 5: Extreme test of vehicle evacuation.

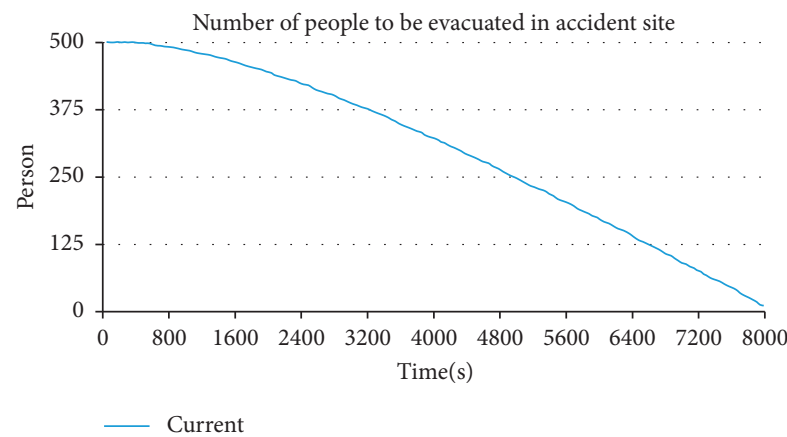

(a)

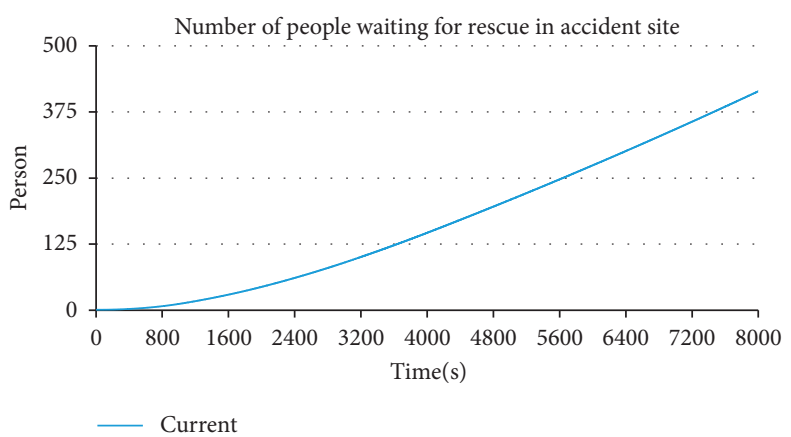

(b)

FiguRE 6: Extreme test of personnel rescue and evacuation. (a) Number of people to be evacuated when the pedestrian free-flow speed is 0. (b) Number of people waiting for rescue when pedestrian free-flow speed is 0 . 


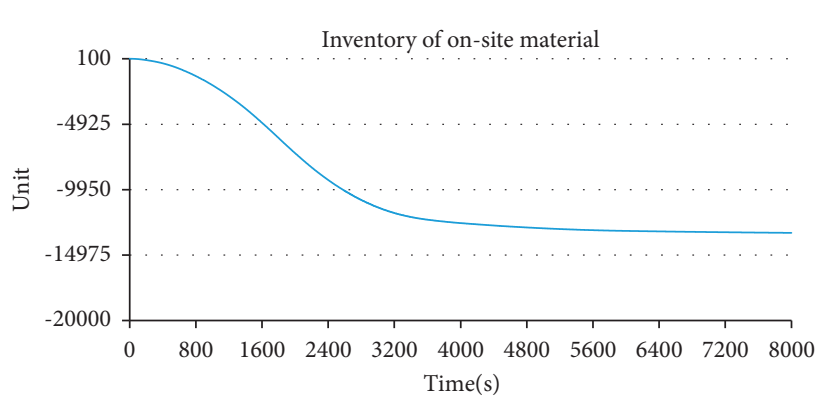

- Current

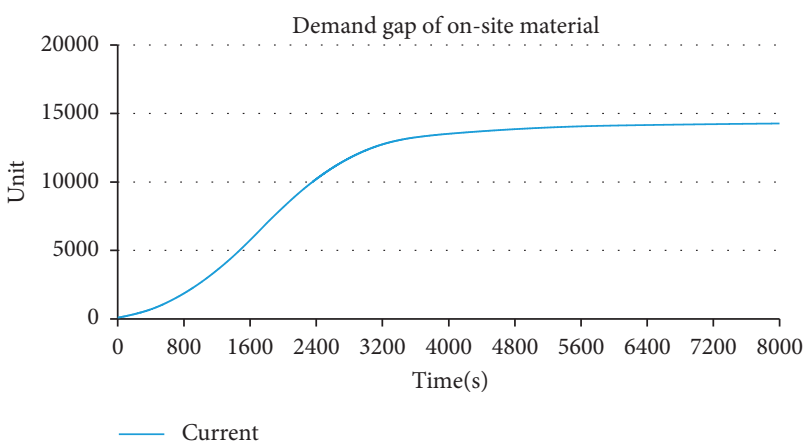

(b)

FiguRE 7: Extreme test of rescue materials delivery. (a) Inventory of on-site material when the capacity per vehicle is 0 . (b) Demand gap of material when the capacity per vehicle is 0 .

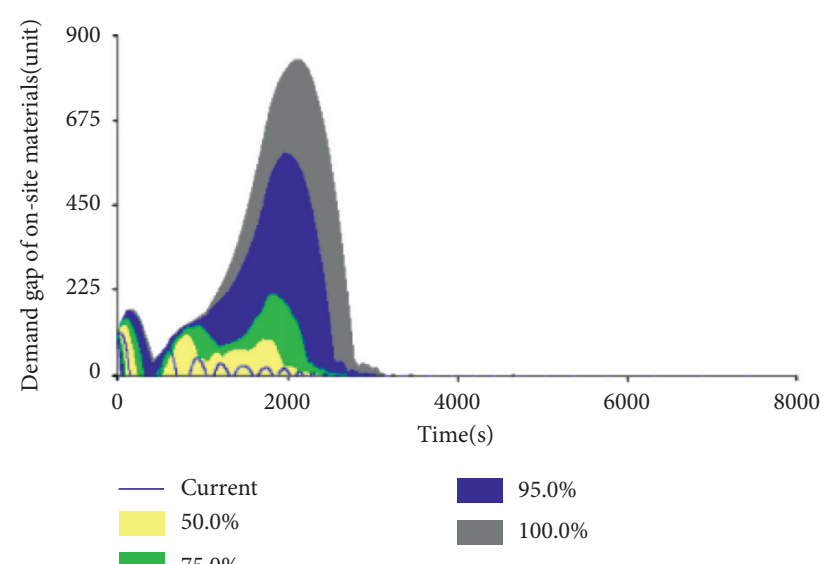

(a)

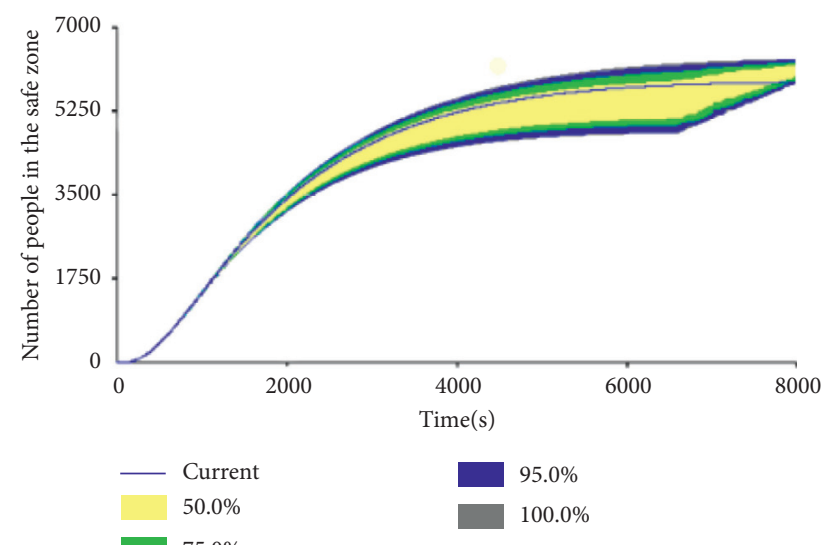

(c)

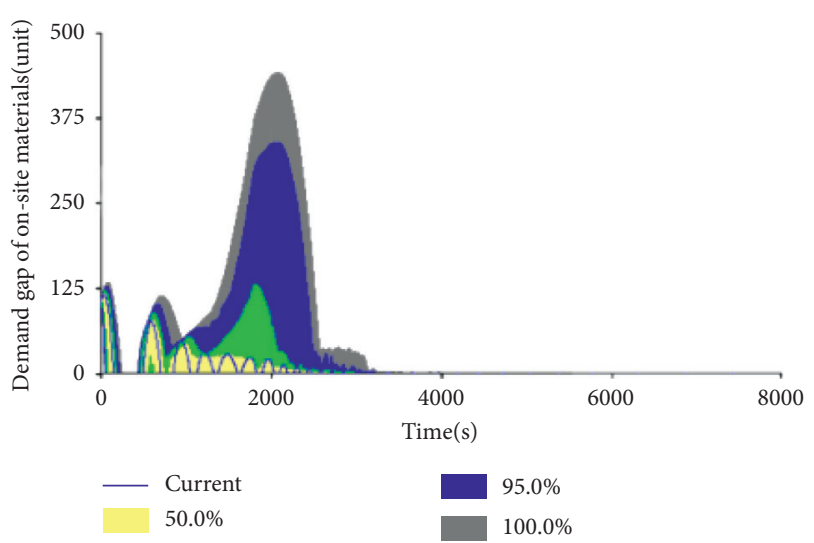

(b)

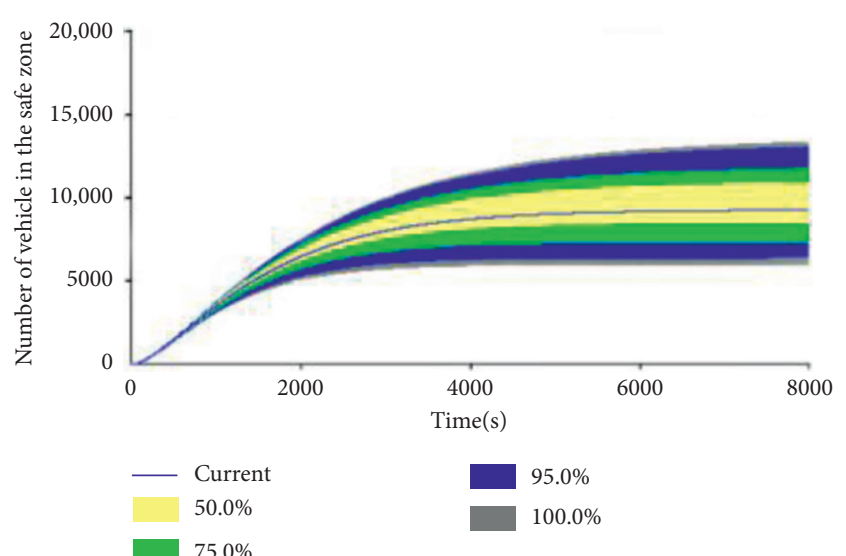

(d)

Figure 8: Continued. 


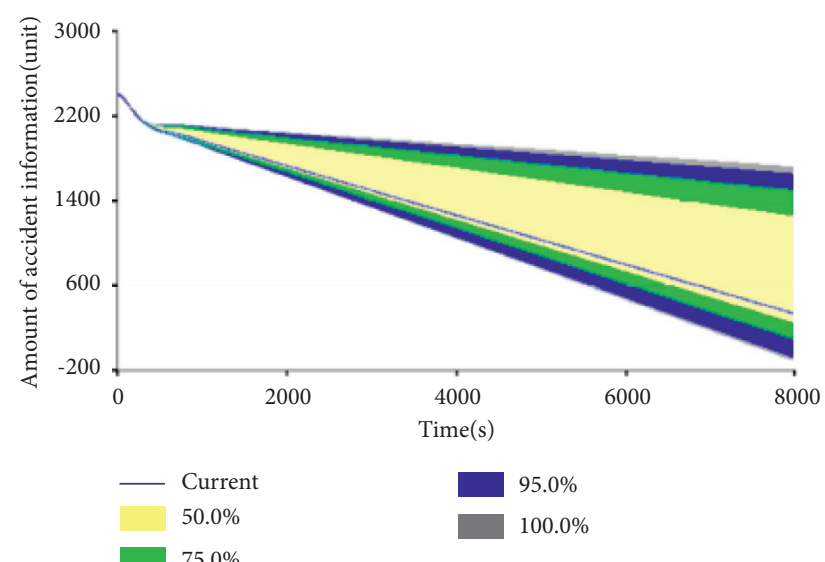

(e)

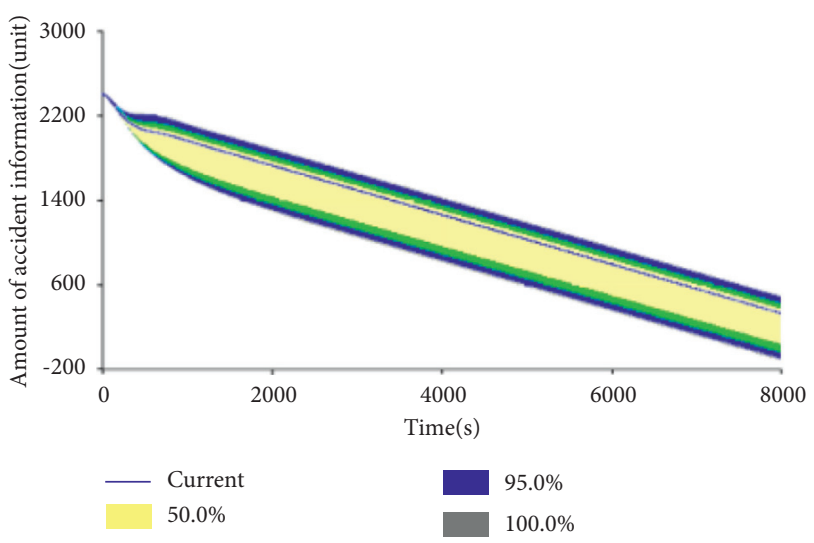

(f)

Figure 8: Sensitivity analysis results. (a) Transportation distance as test parameter. (b) Degree of mechanical modernization as test parameter. (c) Delay time of personnel control as test parameter. (d) Delay time of traffic information release as test parameter. (e) Command level coefficient as test parameter. (f) Delay time of department arrival as test parameter.

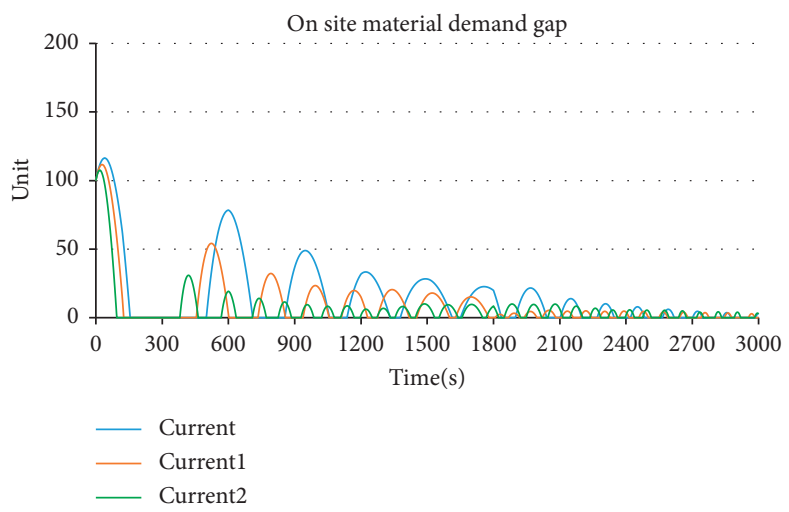

FIgURE 9: Strategy to shorten transportation distance.

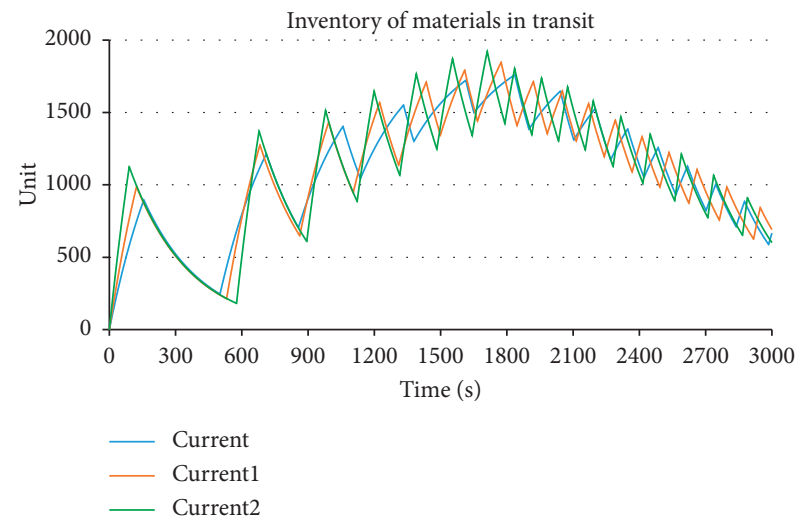

(a)

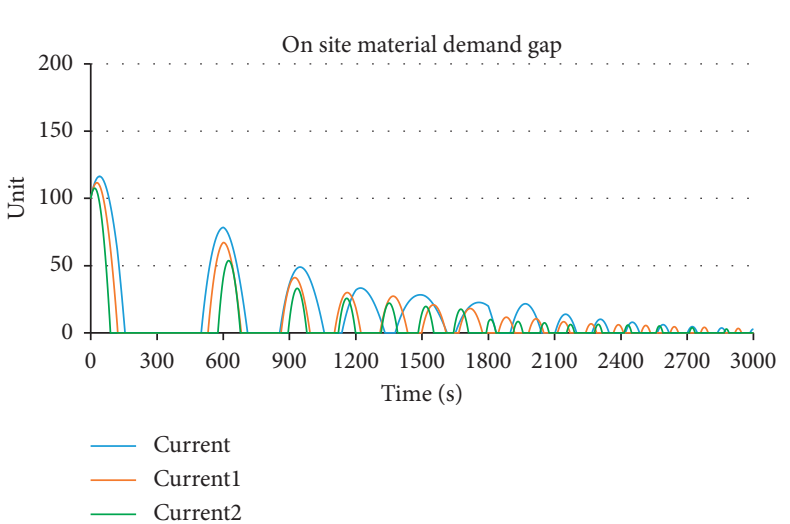

(b)

FIGURE 10: Strategy to improve the degree of mechanical modernization. (a) Inventory of materials in transit. (b) Demand gap of on-site materials. 
TABLE 2: Peak stock of materials in transit under different degrees of mechanical modernization.

\begin{tabular}{|c|c|c|c|c|c|c|c|c|c|c|}
\hline \multirow{2}{*}{$\begin{array}{l}\text { Simulation } \\
\text { states }\end{array}$} & \multicolumn{2}{|c|}{ Cycle 1} & \multicolumn{2}{|c|}{ Cycle 2} & \multicolumn{2}{|c|}{ Cycle 3} & \multicolumn{2}{|c|}{ Cycle 4} & \multicolumn{2}{|c|}{ Simulation period } \\
\hline & $\begin{array}{l}\text { Peak value } \\
\text { (unit) }\end{array}$ & $\begin{array}{c}\text { Time } \\
\text { (s) }\end{array}$ & $\begin{array}{l}\text { Peak value } \\
\text { (unit) }\end{array}$ & $\begin{array}{c}\text { Time } \\
(s)\end{array}$ & $\begin{array}{l}\text { Peak value } \\
\text { (unit) }\end{array}$ & $\begin{array}{c}\text { Time } \\
\text { (s) }\end{array}$ & $\begin{array}{l}\text { Peak value } \\
\text { (unit) }\end{array}$ & $\begin{array}{l}\text { Time } \\
\text { (s) }\end{array}$ & $\begin{array}{l}\text { Peak value } \\
\text { (unit) }\end{array}$ & $\begin{array}{c}\text { Time } \\
(\mathrm{s})\end{array}$ \\
\hline current & 896.0 & 156 & 1214.0 & 711 & 1404.0 & 1058 & 1551.0 & 1332 & 1760.0 & 1836 \\
\hline current1 & 986.8 & 123 & 1275.0 & 682 & 1433.0 & 993 & 1569.0 & 1224 & 1847.0 & 1774 \\
\hline current 2 & 1125.0 & 90 & 1372.0 & 678 & 1515.0 & 979 & 1648.0 & 1199 & 1922.0 & 1711 \\
\hline
\end{tabular}

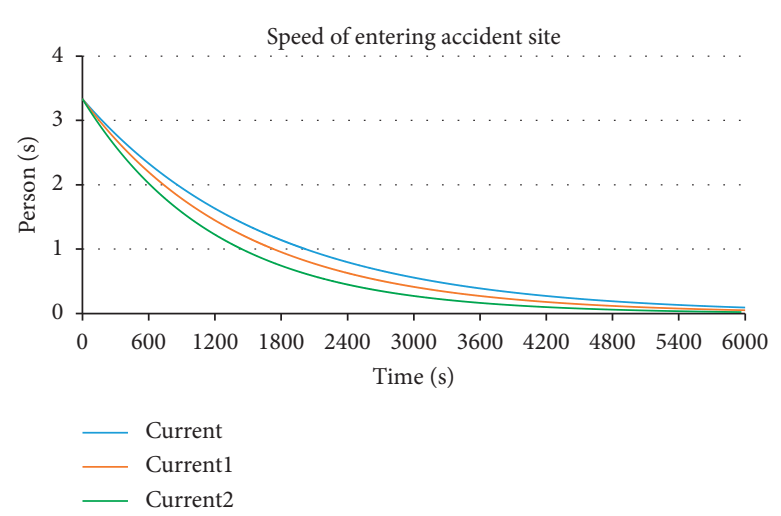

(a)

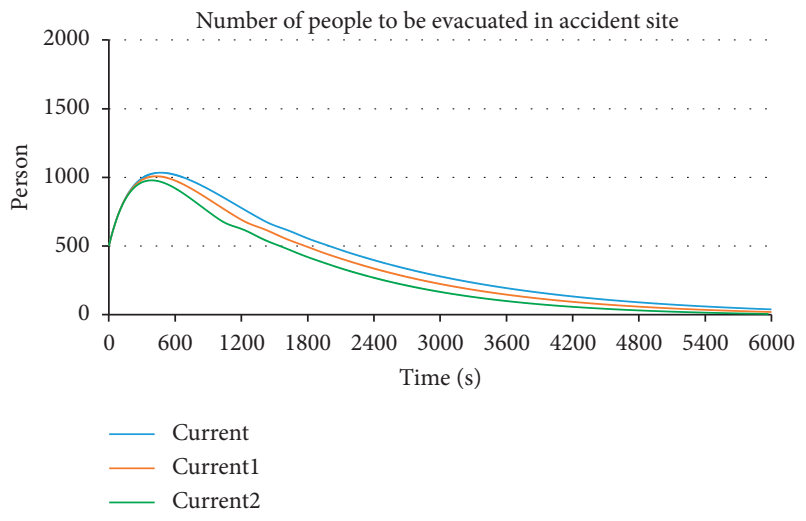

(b)

Figure 11: Strategy to shorten the delay time of personnel control. (a) Speed of entering accident site. (b) Number of people to be evacuated in accident site.

("pending evacuation") with the delay time of personnel control, the delay time of personnel control is assumed as $840 \mathrm{~s}, 600 \mathrm{~s}$, and $360 \mathrm{~s}$, corresponding to current, current1, and current2, respectively, as shown in Figure 11.

In current 2 state, the speed of entering accident site has been reduced to 0 at $5967 \mathrm{~s}$; that is, there are no more off-site people entering the accident site. In contrast, there are still people entering at $6000 \mathrm{~s}$ at 0.0516 people/s (current 1 ) and 0.0936 people/s (current) respectively. The peak numbers of people to be evacuated in accident site are 1034, 1008, and 978 in current, current1, and current2, respectively. It can be seen that the earlier personnel control is started after the accident, the more effective it is to reduce the speed of personnel entering accident site as soon as possible. The number of people to be evacuated from the affected area is then reduced, thereby effectively lowering the difficulty of personnel evacuating.

4.4. Strategy 4: Shortening the Delay Time of Traffic Information Release. To simulate changes in the speed of vehicles entering accident site and the number of vehicles to be evacuated ("pending evacuation") with delay time of traffic information release, the delay time of traffic information release is assumed as $720 \mathrm{~s}, 480 \mathrm{~s}$, and $240 \mathrm{~s}$, corresponding to current, current1, and current2, respectively, as shown in Figure 12.

Shortening the delay time of traffic information release can faster reduce the speed of vehicles entering the accident site. Three simulation states reach 0 at $7945 \mathrm{~s}, 7740 \mathrm{~s}$, and 6299 s. In addition, the number of vehicles to be evacuated was reduced, with the peak values of 2026, 1952, and 1865, respectively.

4.5. Strategy 5: Improving the Command Level Coefficient. To simulate changes in the speed of action execution and the information quantity of accident site with the command level coefficient, the command level coefficient is assumed as $1.05,1.10$, and 1.15 , corresponding to current, current1, and current2, respectively (see Figure 13).

With the improvement of command level and the full cooperation of various departments, the speeds of action execution speed are improved to 1.265 units/s, 1.326 units/s, and 1.386 units/s, respectively. The amount of disposal information in accident site also increases accordingly.

In terms of decision-making and command in emergency management, relevant departments are advised to flexibly use the automation and informatization technology and then to jointly deploy and control emergency activities through the whole processes including information collection, processing, analysis, instruction transmission and execution, and action monitoring. Improving the command level is conducive to fully mobilize the interaction between various departments and reduce the delay in emergency response caused by the untimely information transmission between relevant departments, thereby reducing accidental losses.

4.6. Strategy 6: Shortening the Delay Time of Department Arrival. To simulate changes in the speed of action execution and the information quantity of accident site, the 


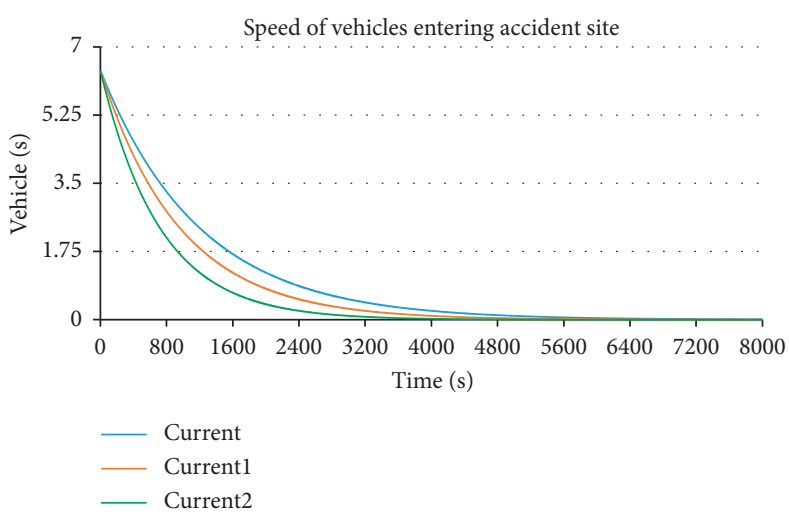

(a)

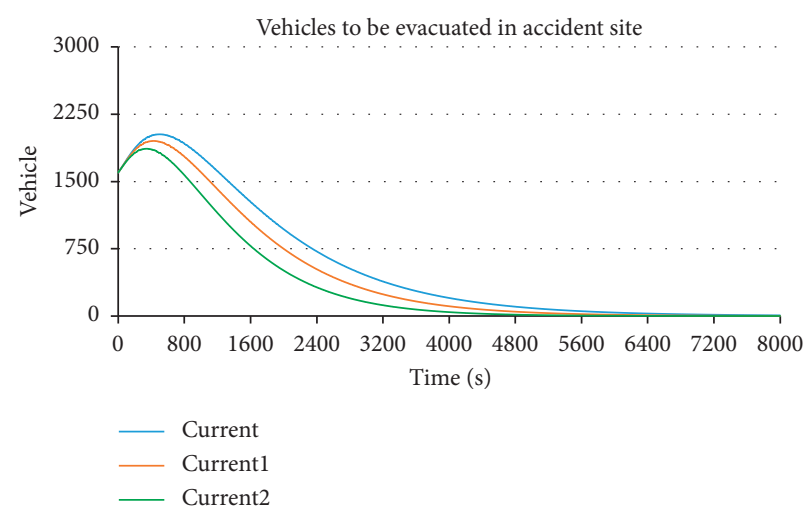

(b)

Figure 12: Strategy to shorten the delay time of traffic information release. (a) Speed of vehicles entering accident site. (b) Vehicles to be evacuated in accident site.

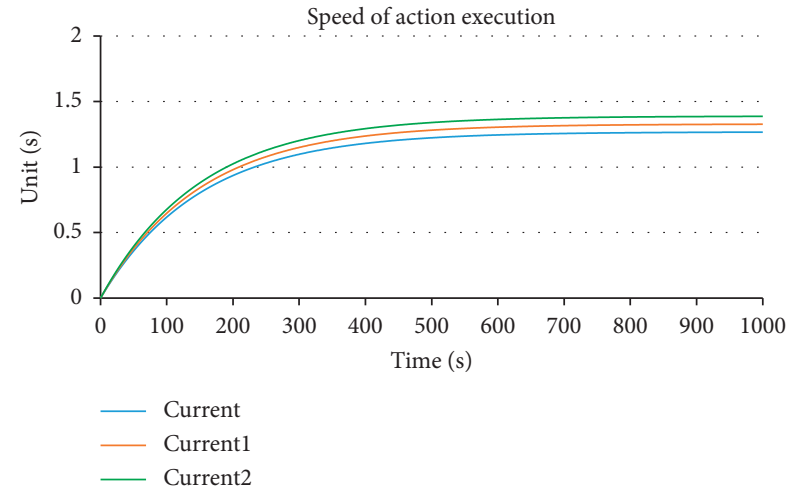

(a)

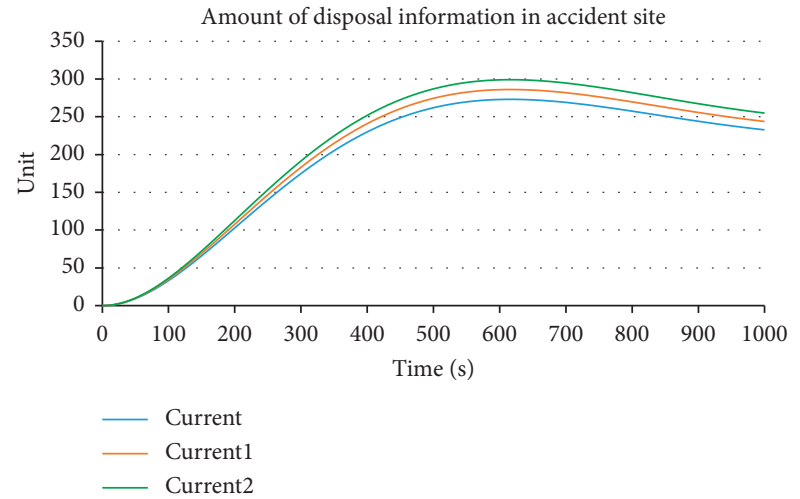

(b)

FIGURE 13: Strategy to improve command level coefficient. (a) Speed of action execution. (b) Amount of disposal information in accident site.

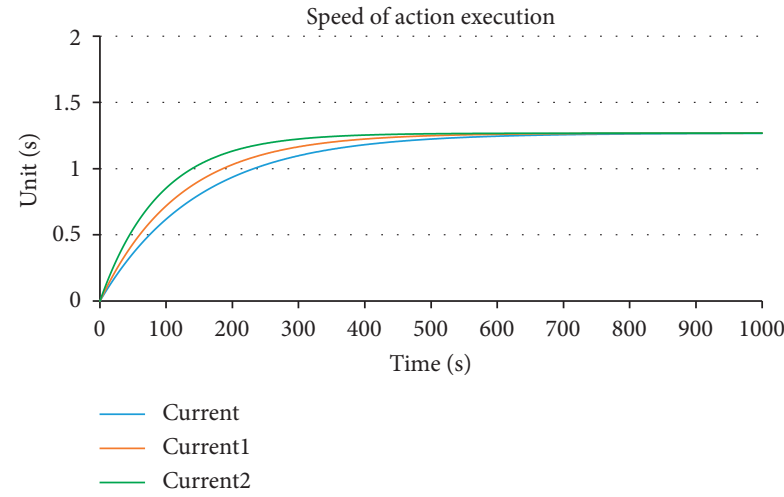

(a)

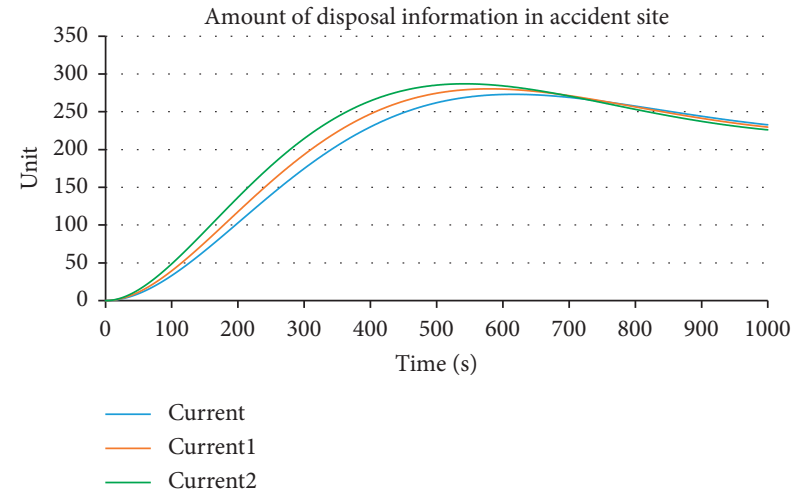

(b)

FIGURE 14: Strategy to shorten the delay time of department arrival. (a) Speed of action execution. (b) Amount of disposal information in accident site.

delay times of department arrival are set to $150 \mathrm{~s}, 120 \mathrm{~s}$, and $90 \mathrm{~s}$, corresponding to current, current1, and current2, respectively, as shown in Figure 14.
The tasks of each relevant department are interrelated in the emergency process. If each department can arrive at accident site faster to carry out emergency disposal, the 
action execution speed can also be increased to the maximum speed in a shorter time, thus more rapidly increasing the amount of disposal information in accident site.

\section{Conclusion}

Taking the road transportation accident of dangerous goods involving the diffusion of toxic gas as an example, the simulation research is carried out, and the variables that are sensitive to the emergency effect and their behavior evolution are obtained. In the proposed model, the accident emergency process is divided into four subsystems including the accident information processing, personnel rescue and evacuation, vehicle evacuation, and rescue materials delivery. The system dynamics model of accident emergency process is established to simulate and observe the dynamic evolution process of system behavior mode. The results showed the following:

(1) The transportation distance between the storage warehouse and accident site is shortened by half, the demand gap of materials decreases, and the time to fill the demand gap is reduced by $39 \%$. When the delay time of department arrival is shortened, the action execution speed is improved at the same time, and the amount of disposal information is also increased. Therefore, the rational layout of emergency rescue facilities and the improvement of the response speed of emergency departments can effectively improve accident emergency capacity.

(2) Shortening the delay time of personnel control can effectively reduce the speed of entering accident site as soon as possible, thereby reducing the number of people to be evacuated and the difficulty of evacuation. According to the simulation, if the delay time of personnel control is shortened by $480 \mathrm{~s}$, the number of people to be evacuated in accident area will be reduced by 56 . Therefore, the emergency management department should conduct activities to enhance public awareness and knowledge about emergency management, including basic hazardous characteristics of dangerous goods, escape skills, and skills for self-rescue and mutual rescue.

(3) According to simulation, the delay time of traffic information release is shortened by 480 s, the number of vehicles to be evacuated is reduced by 74 , and the time when the vehicle stops entering accident area is $1646 \mathrm{~s}$ in advance. The command level coefficient increases by $9.5 \%$, and the speed of action execution increases by $9.6 \%$. The level of mechanical modernization is doubled, the peak inventory of materials in transit will increase by $9.2 \%$, and the time to reach the peak will be shortened by $6.8 \%$. Therefore, we should strengthen the emergency drill activities, fully mobilize the interaction between various departments, and pay attention to the improvement of emergency command level, meanwhile, improving the layout of traffic information release systems such as variable information boards to speed up the dissemination of information. Furthermore, relevant departments are advised to adopt automation, information technology, and other advanced technologies to improve the storage and shipping of emergency supplies.

However, the ability of emergency disposal and management of road transportation accidents of dangerous goods involves many disciplines and fields. The system dynamics model established in this paper still has some shortcomings. In the future, more influencing factors and structural relationships can be considered according to the needs of practical application. In addition, the combination of system dynamics theory and other methods can be utilized to make the model perform better in dealing with practical complex system problems.

\section{Data Availability}

The data used to support the findings of this study are included within the article.

\section{Conflicts of Interest}

The authors declare no potential conflicts of interest with respect to the research, authorship, and/or publication of this article.

\section{Acknowledgments}

This work was supported by the Opening Project of Key Laboratory of Operation Safety Technology on Transport Vehicles, Ministry of Transport, PRC, no. 2020-8407.

\section{References}

[1] B. Fabiano, F. Currò, A. P. Reverberi, and R. Pastorino, "Dangerous good transportation by road: from risk analysis to emergency planning," Journal of Loss Prevention in the Process Industries, vol. 18, no. 4-6, pp. 403-413, 2005.

[2] O. Berman, V. Verter, and B. Y. Kara, "Designing emergency response networks for hazardous materials transportation," Computers \& Operations Research, vol. 34, no. 5, pp. 13741388, 2007.

[3] G. Chen and B. Shuai, "Traffic evacuation of cellular network after dangerous goods spill," Journal of Transportation Systems Engineering and Information Technology, vol. 12, no. 4, pp. 143-148, 2012.

[4] M. Kinateder, D. Gromer, P. Gast et al., "The effect of dangerous goods transporters on hazard perception and evacuation behavior-A virtual reality experiment on tunnel emergencies," Fire Safety Journal, vol. 78, no. 7, pp. 24-30, 2015.

[5] W. Huang, L. Li, H. Liu, R. Zhang, and M. Xu, "Defense resource allocation in road dangerous goods transportation network: a self-contained Girvan-Newman algorithm and mean variance model combined approach," Reliability Engineering \& System Safety, vol. 215, no. 2, 2021.

[6] Y. Qiu, M. Shi, X. Zhao, and Y. Jing, "System dynamics mechanism of cross-regional collaborative dispatch of emergency supplies based on multi-agent game," Complex \& Intelligent Systems, pp. 1-12, 2021. 
[7] J. Li, W. W. Zhang, X. Y. Bai, and S.-M. Li, "System-dynamicsbased factor analysis for the speed of emergency materials transportation," Systems Engineering-Theory \& Practice, vol. 35, no. 3, pp. 661-670, 2015.

[8] L. Gong and J. Zhang, "System-dynamics-based emergency transportation strategy analysis for oil products," Systems Engineering-Theory \& Practice, vol. 37, no. 9, pp. 2256-2267, 2017.

[9] Z. Wang and J. Zhang, "An evaluation of emergency materials mobilization potential based on system dynamics," Systems Engineering-Theory \& Practice, vol. 39, no. 11, pp. 2880-2895, 2019.

[10] H. Shao, H. Zhao, and F. Hu, "A study on modeling and simulation engineering of emergency resources supply based on System Dynamics," Systems Engineering Procedia, vol. 5, pp. 307-312, 2012.

[11] S. Y. Xu, J. H. Wang, J. Li, Y. Wang, and Z. Wang, "System dynamics research of non-adaptive evacuation psychology in toxic gas leakage emergencies of chemical park," Journal of Loss Prevention in the Process Industries, vol. 72, no. 7, 2021.

[12] G. D. Schiff, "System dynamics and dysfunctionalities: levers for overcoming emergency department overcrowding," Academic Emergency Medicine, vol. 18, no. 12, pp. 1255-1261, 2011.

[13] S. Mcavoy, A. Staib, and G. Treston, "Can a system dynamics model of the emergency department show which levers reduce bottlenecks and delays to improve access to care?" Systems Research and Behavioral Science, vol. 38, no. 1, pp. 61-79, 2021.

[14] E. Romano, G. Guizzi, and D. Chiocca, "A decision support tool, implemented in a system dynamics model, to improve the effectiveness in the hospital emergency department," International Journal of Procurement Management, vol. 8, no. 1-2, pp. 141-168, 2015.

[15] D. C. Lane, C. Monefeldt, and J. V. Rosenhead, "Looking in the wrong place for healthcare improvements: a system dynamics study of an accident and emergency department," Journal of the Operational Research Society, vol. 51, no. 5, pp. 518-531, 2000.

[16] N. S. Mohd Yusoff, C.-Y. Liong, A. Y. Md Noh, W. R. Ismail, and N. Ahmad, "Model sistem dinamik untuk meramalkan bilangan pesakit dan keperluan sumber tenaga di Zon kuning jabatan kecemasan," Sains Malaysiana, vol. 48, no. 4, pp. 909-920, 2019.

[17] B. Romana, F. Christian, G. Manfred, and P. Hirsch, "Training decision-makers in flood response with system dynamics," Disaster Prevention and Management, vol. 25, no. 2, pp. 118-136, 2016.

[18] L.-H. Li, Research on the Theory and Method of Material Agile Mobilization, Beijing Institute of Technology, Beijing, China, 2006. 